\title{
Research on the Mechanical and Acoustic Properties of Porous Aluminum for Noise Reduction in Substation
}

\author{
Haoyang $\mathrm{Du}^{1, \mathrm{a}}$, Xin $\mathrm{Su}^{2, \mathrm{~b}}$, Xin $\mathrm{Chen}^{3, \mathrm{c}}$, Jingkai $\mathrm{Nie}^{3, \mathrm{c}}$, Xiaofeng Kong, \\ Qingshan $\mathrm{Xu}^{3, \mathrm{c}}$,Bin Wang ${ }^{3, \mathrm{c}}$, Yonghe Tang ${ }^{3, \mathrm{c}}$ \\ ${ }^{1}$ Electric Power Research Institute of JLEP,SGCC,Changchun, China \\ 2 Jilin Electric Power Scientific Research Institute Co., Ltd.,Changchun, China \\ ${ }^{3}$ State Grid Smart Grid Research Institute, Beijing, China \\ State Grid Smart Grid Research Institute, Beijing, China \\ State Grid Zhejiang Electric Power Company Jinhua Power Supply Company, Zhejiang,China \\ State Grid Zhejiang Electric Power Company Jinhua Power Supply Company, Zhejiang,China \\ State Grid Jilin Electric Power Co., Ltd.,Changchun, China \\ Jilin Electric Power Technology Development Company, Changchun, China \\ a1289307576@qq.com, b771450514@qq.com,, seasung1973@sina.com \\ jknie@emails.bjut.edu.cn,jhkxf@sina.com.cn,550562399@qq.com,Spxuqs@163.com \\ 18946500065@189.cn
}

\begin{abstract}
Keywords: noise reduction; porous aluminum; mechanical properties; acoustic properties; power substation equipments

Abstract. Noise from the power substation is an arousing environmental issue in recent years. Noise has also been strictly required by GB12348-2008. Noise measuring on certain power substation stations show that noise indices in most stations exceed the Class 1 level according to GB12348-2008. Porous aluminum for reducing noises from power transmission station has been researched in this paper. The suitable way is to upgrade the noise reduction system for existing stations. Compared with traditional noise reduction materials, porous aluminum shows priorities in low mass, environmental protection and recyclable. Mechanical properties and acoustic properties have been researched and the results meet the requirements of State Standard. The research proves that porous aluminum to be an applicable noise reduction material for power substation station.
\end{abstract}

\section{Introduction}

With the acceleration of urbanization in recent years, the industrial and residential requirement on electricity is increasing. More and more power substation has been arranged in the central area of large cities. Due to the shortage of lands, some power substations have been constructed near the residential area. The complaint on power substation noise from resident is increasing. In 2008, a new state standard for industrial enterprises noise at boundary has been issued, which proposed more restrict requirements Reducing noise from existing power substation is a new issue face by power supply enterprises.

According to physics definition, vibrations totally without periodical amplitude and frequency are called noises. In the field of environmental protection, all the not required sounds are called noise. For an example, noise in power substation are caused by the vibration of steel cores of the main transformer, shunt reactor and the noises from power distribution devices and breakers.

In 2012 we have finished noise measuring and statistics for certain transformers. According to the city results of city A, the daytime noise off the boundary of $220 \mathrm{kV}$ primary indoor substation is $59.0 \mathrm{~dB}$ and the nighttime noise is $48.3 \mathrm{~dB}$. In city $\mathrm{B}$, the daytime noise off the boundary of $220 \mathrm{kV}$ primary indoor substation is $58.9 \mathrm{~dB}$ and the nighttime noise is $43.2 \mathrm{~dB}$. Statistics among 400 substations of 
$220 \mathrm{kV}$ show that most of the noise index exceeds class I standards. The best method to reduce the noise of these substations is applying noise reduction structures. This paper has researched on reducing noise of substations by porous aluminum. The microstructure and acoustic properties of porous aluminum are introduced below.

\section{The mechanical properties of porous aluminum}

Morphology. The cell morphology of porous aluminum in this paper is shown in Fig.1.1. As we can see, the holes of porous aluminum are not exactly in the same size. Further observation shows that, the shape of the hole is more like a polygon when its size is bigger; and it is more like a roundness or oval when its size is smaller.

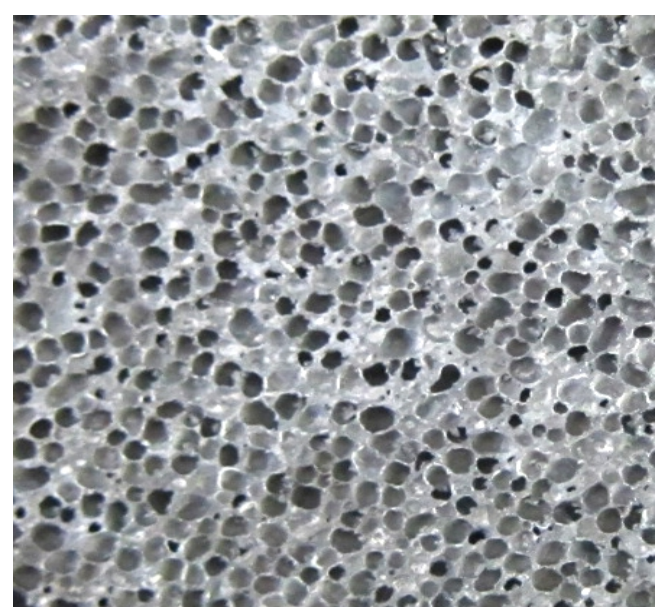

Fig.1.1 Surface morphology of porous aluminum in this paper

The compression test of porous aluminum. The compression test in this paper is accomplished by the AG-I 500KN microcomputer control electronic universal testing machine. The result is shown in Fig 1.2

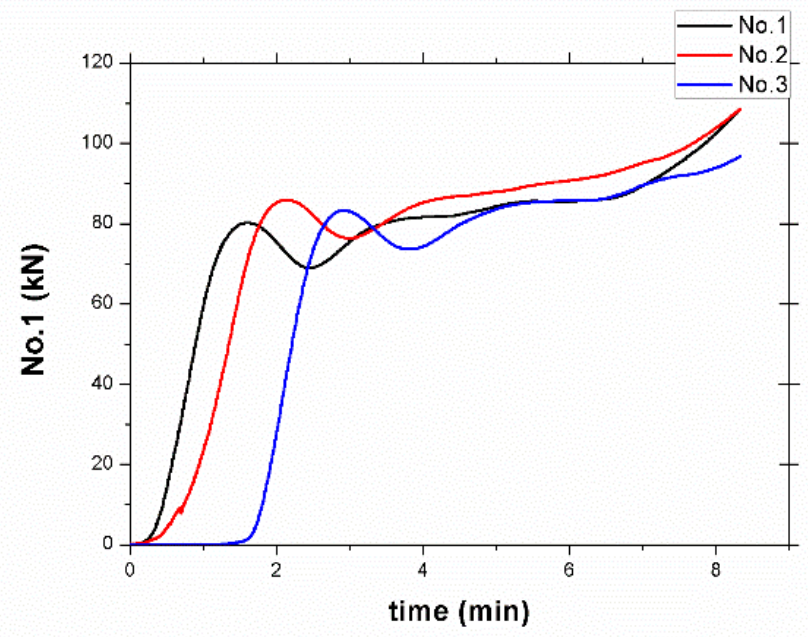

Fig. 1.2 Stress-strain curves of the compression test

According to this test, the following conclusions are obtained: The deformation of porous aluminum under static loading has all have three deforming regions such as elasticity region, plastic collapsing region and densification region. In the plastic collapsing region, porous aluminum keeps low stress , on the other hand, the strain increases a lot; relative density has a great influence on the mechanical properties (such as Young's modulus and Yield strength) of porous aluminum.

The tensile test of porous aluminum. According to the requirements of GB/T7314-2005, the samples are processed into $10 \mathrm{~mm} \times 180 \mathrm{~mm} \times 35 \mathrm{~mm}$ by wire-electrode cutting. The stress-stain curves are shown in Fig.1.3 . 


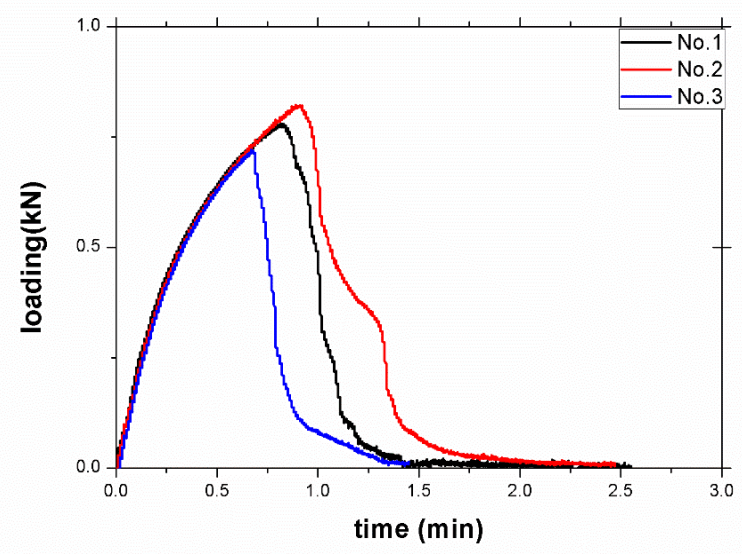

Fig. 1.3 Stress-strain curves of the tensile test

The bending test of porous aluminum. The maximum bending stresses of the sample 1, 2 and 3 are $8.96 \mathrm{~N} / \mathrm{mm}^{2} 、 9.38 \mathrm{~N} / \mathrm{mm}^{2}$ and $8.15 \mathrm{~N} / \mathrm{mm}^{2}$.

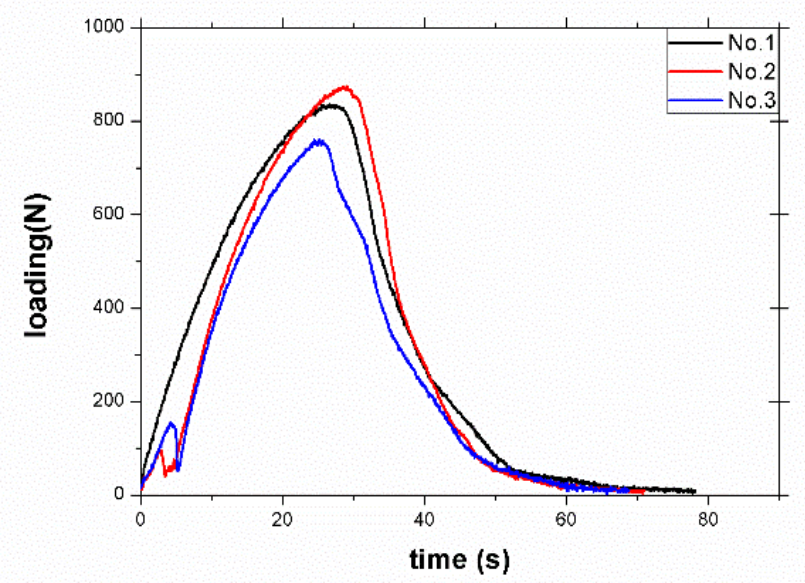

Fig. 1.4 Stress-strain curves of the bending test

By comparing the stress-strain curves of the three samples in Fig 1.4, it is obvious that the maximum bending load of samples in the test is $875 \mathrm{~N}$. We can calculate the value of the maximum stress is $9.37 \mathrm{~N} / \mathrm{mm}^{2}$, and the porous aluminum has great repeatability.

The porosity test of porous aluminum. Porous aluminum was quantized by using based on digital image process and analysis technology. The porosity of the samples are all about $54 \%$, and the holes are uniformly dispersed.

The hardness test of porous aluminum. The stress-strain curves of the three samples are shown in Fig.1.5. The value of stress and hardness are shown in Table 1. 


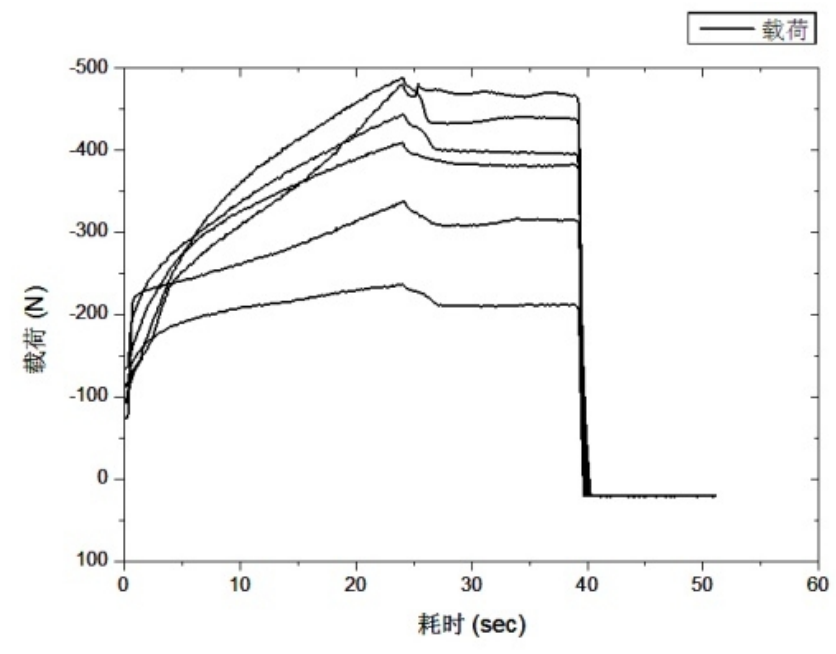

Fig. 1.5 Stress-strain curves of the hardness test

Table 1 The Value of Stress and Hardness

\begin{tabular}{|c|c|c|c|c|c|c|}
\hline No. & 1 & 2 & 3 & 4 & 5 & 6 \\
\hline D & 2373 & 2236 & 2231 & 2232 & 2350 & 2474 \\
\hline F & 469 & 442 & 487 & 406 & 237 & 336 \\
\hline HS & 200.7 & 189.4 & 188.8 & 188.8 & 198.8 & 209.2 \\
\hline
\end{tabular}

The hardness values of the three sample are calculated by the formula of hardness, and the values are all about 200.

\section{Acoustic properties of porous aluminum}

We test the sound absorption coefficient of the porous aluminum sample based on compound sound absorption structure using the reverberation chamber method. The size of the sample is $125 \mathrm{~m} \times 1.11 \mathrm{~m} \times 175 \mathrm{~mm}$. The test is completed by multichannel sound analyzer(B\&K 3160-A-042), microphone (B\&K 4189-A-021) and sound level calibrator ( $B \& \mathrm{~K} 4231$ ). The sample is tested in the Institute of Acoustics of the Chinese Academy of Sciences, and the result is shown in Fig.2.1.

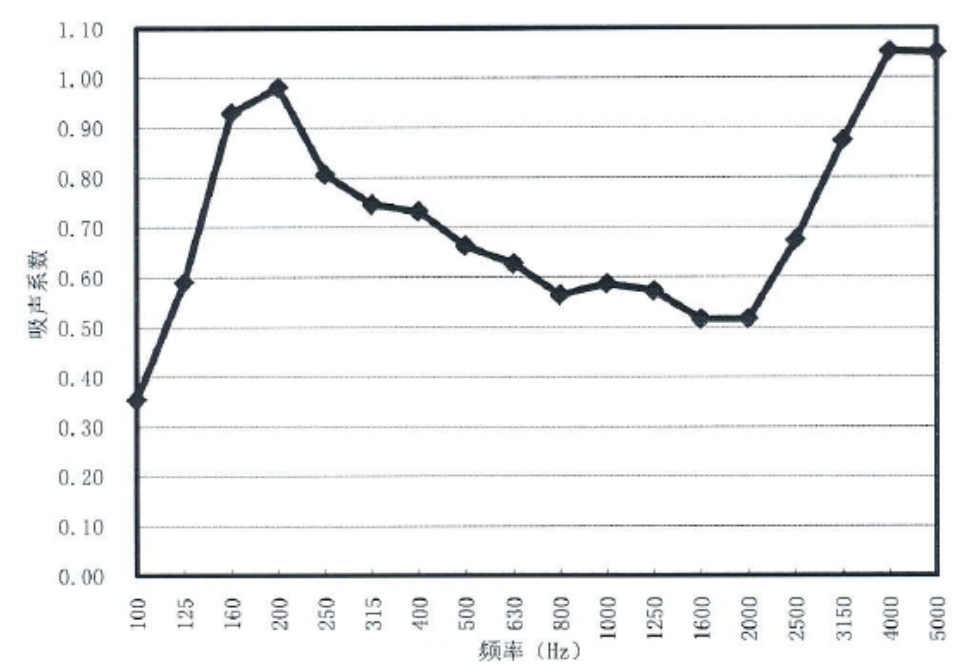

fig.2.1 Sound absorption coefficient curve of the porous aluminum sample (175mm) $1 / 3$ octave band width of the central frequency 100 5000Hz.

The result shows the NRC of porous aluminum sample based on compound sound absorption structure is 0.65 , the value is up to the ISO and the state standard. 


\section{Fireproof property test}

Incombustibility and heat values are also measured. According to the result, the incombustibility is already up to the requirement of GB/T5464-2010 and GB8624-2012. The PCS is also up to the requirement of GB/T14402-2007 (less than or equal to $2.0 \mathrm{MJ} / \mathrm{kg}$ ).

\section{Conclusions}

This paper has developed porous aluminum to reducing noise of substations. We fully discuss the mechanical properties of porous aluminum through the compression test, tensile test, bending test, porosity measuring test, hardness test and microstructure test. We also propose a new method to investigate the uniformity of foam material using technology based on digital image process and analysis. We find out that relative density has big influence on the compressive mechanical properties of porous aluminum. The maximum stress value of the sample is $9.37 \mathrm{~N} / \mathrm{mm}^{2}$, the porosity is about $54 \%$, and the value of hardness is about 200 .

Acoustic properties of porous aluminum is discussed by the reverberation chamber method .The NRC of the sample $(175 \mathrm{~mm})$ is 0.65 ,and the Rw is already up to the Class 2 level in the GB 50118-2010（be equal or greater than $45 \mathrm{~dB}$ ).

According to the tests, the incombustibility and the PCS of the sample are both up to the requirement of A1 level in the state standard.

\section{References}

[1]Liu PS, Lang KM. Functional materials of porous metals made by P/M, electroplating, and some other techniques. J Master Sci. 2001;36(21):5059-72.

[2]Nakajima H. Fabrication, properties, and applications of porous metals with directional pores. Proc Jpn Acad B Phys Bio Sci 2010;86(9):994-99.

[3]Davies GJ, Shu Z. Metallic foams: their production, properties, and applications. J Mater Sci 1983;18:1899-911.

[4]Tang HP, Zhang ZD. Developmental states of porous metal materials. Rare Metal Mat Eng 1997;26(1);1-6.

[5]Banhart J, Baumeister J, Weber M. Metal foams near commercialization. Met Powder Rep 1997;52(4):38-41.

[6]Bray H. Design opportunities with metal foam. Eng Mat Des 1972;16(1):19.

[7]Banhart J, Seeliger HW. Aluminum foam sandwich panels: manufacture, metallurgy and applications. Adv Eng Mat 2008;10(9):792-802. 